\title{
Postural change of IOP in normal persons and in patients with primary wide open-angle glaucoma and low-tension glaucoma
}

\author{
SHIGEO TSUKAHARA AND TAKAYA SASAKI \\ From the Departments of Ophthalmology, Yamanashi Medical College, Yamanashi, and the \\ Suwa Red Cross Hospital, Nagano, Japan
}

SUMMARY The values of intraocular pressure (IOP) measurements by an Alcon pneumatic tonometer and a Goldmann applanation tonometer were found to be close, with a correlation coefficient of 0.92 . Measured by the pneumatonograph the IOP after 30 minutes in the supine position was highest in normal persons, in patients with primary wide open-angle glaucoma and low-tension glaucoma. The greatest difference in IOP between subjects sitting and supine was observed in patients with low-tension glaucoma.

Many authors have discussed the change of IOP measured by various tonometers in the sitting and supine positions. ${ }^{1-6}$ However, methodologically ${ }^{78}$ Schiøtz's tonometer presents problems in measuring $\mathrm{IOP}^{9}$ in subjects sitting down, and there is also the problem of scleral rigidity. ${ }^{10}$ The reported data showed that there was an average rise in IOP of about 1 to $2 \mathrm{mmHg}$ in subjects lying down. ${ }^{11-15}$ The best method is to employ an Alcon pneumatic tonometer for measuring IOP in subjects either sitting or lying down. ${ }^{16-18}$ It is very important in the treatment of glaucoma patients to know the postural change of IOP.

The purpose of this paper is to report the postural change of IOP in normal persons and in patients with primary wide open-angle glaucoma and low-tension glaucoma by measuring it with an Alcon pneumatic tonometer.

\section{Materials and methods}

The materials consisted of 20 normal persons (average age $67 \cdot 6$, SD $13 \cdot 1$ years), 20 patients with primary wide open-angle glaucoma (average age $60 \cdot 8$, SD 20.6 years), and five patients with low-tension glaucoma (average age 63.3, SD 16.8 years).

An Alcon pneumatic tonometer was used for both the sitting and the supine positions. A Goldmann Correspondence to Professor S. Tsukahara, Department of Ophthalmology, Yamanashi Medical College, Tamaho, Yamanashi, Japan 409-38. tonometer was used only for the sitting position. In 20 normal eyes the relationship between the IOP measurement with the Goldmann tonometer and the Alcon pneumatonograph (PTG) was examined in the sitting position. In all procedures one drop of $0.4 \%$ oxybuprocaine was instilled into both eyes. The IOP was measured in the right eye in the same room between 10 and 12 o'clock in the morning. No pillow was allowed. Glaucoma patients had not received treatment for 3 days prior to the test.

The order of the measurements is shown in Fig. 1. First, Goldmann applanation readings were taken with the subjects seated. Immediately after that IOP

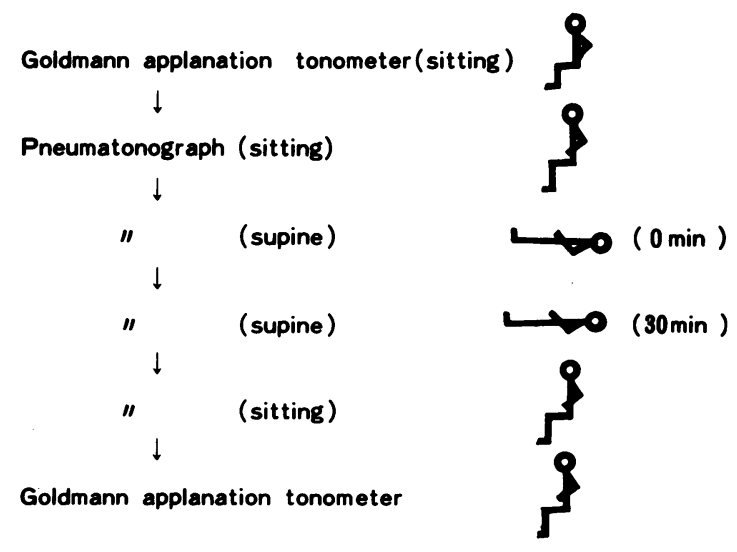

Fig. 1 Order of measurements. 


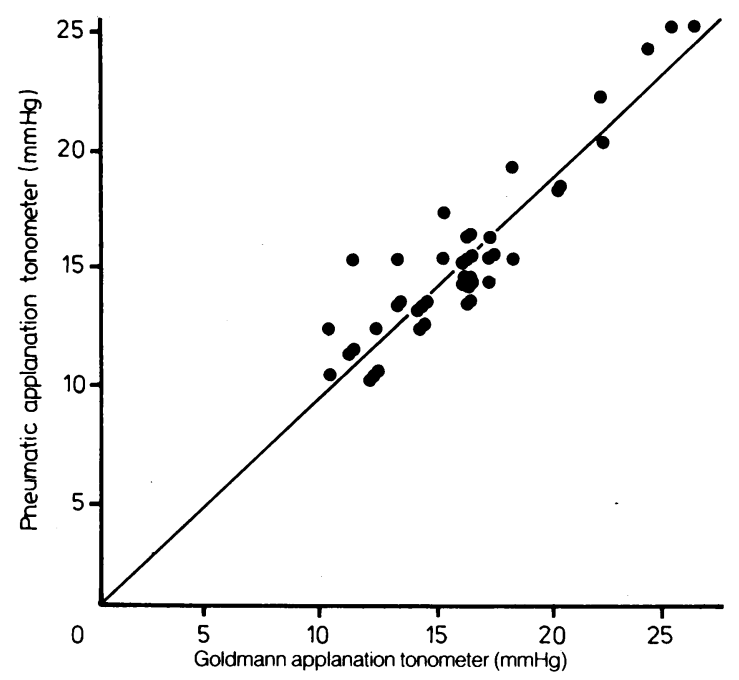

Fig. 2 Comparative IOP measurements using Goldmann applanation and Alcon pneumatic tonometer with patients seated. Number of eyes $=45$. Correlation coefficient $=0.91$. Regression equation $y=0 \cdot 12+0 \cdot 93 x$. Goldmann applanation tonometry $-P T G=0.91(S D 1.53) \mathrm{mmHg}$.

was measured with PTG in the same position. The patients then lay flat on the bed without a pillow about $1 \mathrm{~m}$ away from the tonometer and were measured again with PTG. They were measured again with PTG after 30 minutes. Finally, the subjects sat in the chair in front of the slit-lamp and were measured again for IOP with PTG and the Goldmann tonometer.

The Alcon pneumatonometer was calibrated each day before use. The value of measurements with PTG was judged by the mean level of the recorded pulse wave. All measurements were made by the same examiner.

\section{Results}

Fig. 2 shows the correlation between Goldmann applanation and the PTG tonometer on subjects in the sitting position. The mean difference in IOP between the Goldmann applanation tonometer and the PTG tonometer was $2 \cdot 8, \mathrm{SD} 0.83 \mathrm{mmHg}$. The former tended to be higher than the latter. Both were in close agreement with a correlation coefficient of 0.92 . In the conrols the mean applanation IOP recorded in the sitting position with the PTG tonometer was $13 \cdot 0$, SD $1 \cdot 86 \mathrm{mmHg}$, and $14 \cdot 0, \mathrm{SD} 2 \cdot 14$ $\mathrm{mmHg}$ with the Goldmann applanation tonometer (Table 1).

The IOP measured after 30 minutes in the supine position by PTG tonometry was highest in normal persons, lower in the patients with primary wide open-angle glaucoma and with low-tension glaucoma (Tables 1, 2, 3).

The mean difference in IOP between the sitting and supine positions was $5.6, \mathrm{SD} 1.71 \mathrm{mmHg}$ in the normal persons, $6 \cdot 5, \mathrm{SD} 2.66 \mathrm{mmHg}$ in the patients with primary wide open-angle glaucoma, and $8 \cdot 6, \mathrm{SD}$ $3.5 \mathrm{mmHg}$ in the patients with low-tension glaucoma (Fig. 3). It should be pointed out that the most significant difference was observed in the patients with low-tension glaucoma.

\section{Discussion}

Many authors have reported on the correlation of IOP between the Goldmann and the Alcon PTG. ${ }^{18-22}$ Some of them used the Goldmann tonometer with subjects in the sitting position and the Schiøtz tonometer for the supine position. In these experiments the Goldmann tonometer proved of more value than the PTG. Moreover, some of the workers observed that the rise in pressure when patients become supine is higher in glaucomatous eyes. ${ }^{11216}$ We have confirmed this, and the IOP by the Alcon PTG was $1.5 \mathrm{mmHg}$ greater than by the

Table 1 Normal eyes (20 eyes, average ages $67 \cdot 6$, $S D 13 \cdot 1 \mathrm{yr}$ )

\begin{tabular}{ll}
\hline & $1 O P \mathrm{mmHg}( \pm S D)$ \\
\hline Goldmann applanation tonometry (sitting) & $14 \cdot() \pm 2 \cdot 14$ \\
Pncumatonograph (sitting) & $13 \cdot() \pm 1 \cdot 86$ \\
Pncumatograph (supine) & $16 \cdot 9 \pm 2 \cdot 63$ \\
Pncumatograph (30 min supinc) & $18 \cdot 9 \pm 2 \cdot 65$ \\
Pncumatograph (sitting) & $13 \cdot 1 \pm 2 \cdot 52$ \\
Goldmann applanation tonometry (sitting) & $13 \cdot 8 \pm 2 \cdot 52$ \\
\hline
\end{tabular}

Table 2 Primary wide open angle glaucoma eyes (20 eyes, average ages $60 \cdot 8, S D 20 \cdot 6 \mathrm{yr}$ )

\begin{tabular}{ll}
\hline & $\mathrm{IOP} \mathrm{mmHg}( \pm S D)$ \\
\hline Goldmann applanation tonometry (sitting) & $18 \cdot 3 \pm 3 \cdot 42$ \\
Pncumatonograph (sitting) & $17 \cdot 1 \pm 4 \cdot(0)$ \\
Pncumatograph (supinc) & $20 \cdot 3 \pm 4 \cdot 15$ \\
Pncumatograph (30 min supinc) & $23 \cdot 6 \pm 5 \cdot 20$ \\
Pncumatograph (sitting) & $18 \cdot 6 \pm 4 \cdot 72$ \\
Goldmann applanation tonometry (sitting) & $19 \cdot 1 \pm 4 \cdot 44$ \\
\hline
\end{tabular}

Table 3 Low-tension glaucoma eyes (5 eyes, average ages $63 \cdot 3, S D$ I6.8 yr)

\begin{tabular}{ll}
\hline & IOP $\mathrm{mmHg}( \pm S D)$ \\
\hline Goldmann applanation tonometry (sitting) & $13 \cdot 0 \pm 1 \cdot 67$ \\
Pncumatonograph (sitting) & $13 \cdot 8 \pm 2 \cdot 40$ \\
Pncumatograph (supinc) & $19 \cdot 8 \pm 1 \cdot 94$ \\
Pncumatograph (30 min supinc) & $22 \cdot 4 \pm 1 \cdot 62$ \\
Pncumatograph (sitting) & $15 \cdot() \pm 0 \cdot()()$ \\
Goldmann applanation tonometry (sitting) & $13 \cdot 4 \pm 1 \cdot 50$ \\
\hline
\end{tabular}




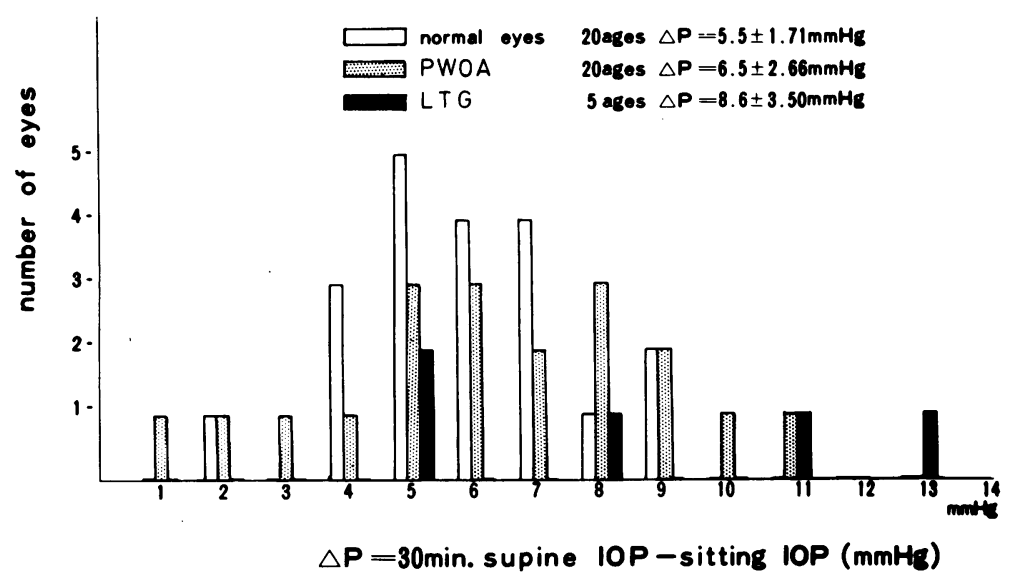

Fig. 3 Histogram of pressure differential between patients sitting and lying down.

Goldmann tonometer in the same position. This difference is thought to be due to the correction of gain in the PTG tonometer.

At present it is generally accepted that measurements of IOP in the sitting and supine positions are best taken with the Alcon PTG. However, some problems still remain. Krieglstein et al. ${ }^{22}$ found a non-linear relationship between IOP increase and body position by measuring IOP in different body positions from $60^{\circ}$ semiupright to $30^{\circ}$ with the head down. The IOP postural response in individual subjects was roughly correlated with ophthalmic arterial pressure and with the episcleral venous pressure postural response. It is concluded that the IOP postural response depends on arterial and venous vascular changes when the subject moves from an erect to a horizontal position. The IOP measured in the supine position will be influenced by the use of a pillow and its thickness though pillows were not used in this study. Various reasons have been given to explain the rise of IOP in the recumbent position.

Weber and Price ${ }^{23}$ found an average rise in the IOP of $6 \mathrm{mmHg}$ in 177 eyes of subjects in the sitting and supine positions by measuring with PTG. They claimed that this increase in the diastolic ophthalmic arterial pressure would be transmitted to the intraocular blood vessels, causing them to dilate. They also indicated the possibility that it might be of importance in the treatment and early detection of glaucoma to demonstrate a larger postural IOP response in glaucomatous eyes. Obtaining a greater postural rise of IOP in a given eye might be another diagnostic factor in glaucoma. ${ }^{162224}$

The effect of placing the head below the body should be investigated in the future. A change of episcleral venous pressure would be expected in carotid cavernous fistula and mediastinal tumour, and in these diseases the postural change of IOP should be examined. Finally, it has been suggested that damage to the optic nerve in low-tension glaucoma might occur when the patient is asleep in the supine position.

We have confirmed the fact that IOP measured with the body in different positions was greater in glaucomatous eyes than in normal eyes, and in patients with low-tension glaucoma the postural difference in IOP particularly was remarkable.

\section{References}

1 Linnér E, Rickenbach C, Werner H. Comparative measurements of the pressure in the aqueous veins and the conjunctival veins using different methods. Acta Ophthalmol (Kbh) 1950; 28: 469-78.

2 Goldmann H, Schmidt Th. Über Applanations-tonometric. Ophthalmologica 1957; 134: 221-8.

3 Weekers R, Lavergne G, Gougnard L. The origin of functional deficiencies in the hypertensive eye. Doc Ophthalmol 1959; 13: 251-60.

4 Drance SM. The coefficient of scleral rigidity in normal and glaucomatous eyes. Arch Ophthalmol 1960; 63: 668-70.

5 Leydecker W. Glaucoma: ein handbuch. Berlin: Springer, 1960: 286.

6 Leith AB. Episcleral venous pressure in tonography. $\mathrm{Br} J \mathrm{Oph}$ thalmol 1963; 47: 271-8.

7 Langham ME, McCarthy E. A rapid pneumatic applanation tonometer: comparative findings and evaluation. Arch Ophthalmol 1968; 79: 389-99.

8 Moses RA. Repeated applanation tonometry. Ophthalmologica $1961 ; 142:$ 663-8.

9 Friedenwald JS. Tonometer calibration: an attempt to remove discrepancies found in the 1954 calibration scale for Schøtz tonometers. Trans Am Acad Ophthalmol Otolaryngol 1957; 61: $108-14$.

10 Roberts W, Rogers W. Postural effects on pressure and ocular rigidity measurements. Am J Ophthalmol 1969; 57: 111.

11 Anderson DR, Grant WM. The influence of position on IOP. Invest Ophthalmol Visual Sci 1973; 12: 204-12.

12 Galin MA, McIvor JW, Magruder GB. Influence of position on IOP. Am J Ophthalmol 1963; 55: 720-3.

13 Tarkkanen A, Leikola J. Postural variations of the IOP as measured with the Mackay Marg tonometer. Acta Ophthalmol 1967; 45: 569-75. 
14 Tsamparlakis J, Casey TA, Howell W, Edridge E. Dependence of IOP on induced hypotension and posture during surgical anaesthesia. Trans Ophthalmol Soc UK 1980; 100: 521-6.

$15 \mathrm{Vaz} F$, Gupta AK. The influence of posture on intraocular pressure. Indian J Ophthalmol 1981; 29: 1-3.

16 Hetland-Eriksen J. On tonometry 5 . The pressure of glaucomatous eyes measured in the sitting and the lying positions by means of the Goldmann applanation tonometer. Acta Ophthalmol (Kbh) 1966 ; 44: 515-21.

17 Hetland-Eriksen J. On tonometry 6. Comparative tonometry with Goldmann applanation tonometer and the Schøtz tonometer in the lying position. Acta Ophthalmol (Khh) 1966; 44: 522-38.

18 Jain JR, Marmion VJ. A clinical evaluation of the applanation pneumatonograph. Br J Ophthalmol 1976; 60: 107-10.
19 Walker RE, Litovitz TL. An experimental and theoretical study of the pneumatic tonometer. Exp Eye Res 1972; 13: 14-23.

20 Walker RE, Litovity TL. Pneumatic applanation tonometer studies. II. Rabbit cornea data. Exp Eye Res 1972; 13: 187-93.

21 Walker RE, Langham ME. Pneumatic applanation tonometer studies. III. Analysis of floating tip sensor. Exp Eye Res 1975; 20: 167-72.

22 Krieglstein GK, Waller WK, Leydecker W. The vascular basis of the positional influence on the IOP. Albrecht von Graefes Arch Klin Ophthalmol 1978; 206: 99-106.

23 Weber AK, Price K. Pressure differential of IOP measured between supine and sitting position. Ann Ophthalmol 1981; 13: 323-6.

24 Wuthrich UW. Postural change and intraocular pressure in glaucomatous eyes. Br J Ophthalmol 1976; 60: 111-14. 